Anat. Inst. d. Mediz. Fak., Univ. Okayama (Vorstand: Prof. M. SEKI).

\title{
Über die durch die intravenöse Injektion von Antibiotika (Sarkomycin, Streptomycin, Achromycin und Terramycin) hervorgerufenen Veränderungen der fibrohistiocytären Ge- meinschaft in der Unterhaut.
}

静脈内に注射された抗生物質（ザルコマインン，ストレプトマインン， アクロマインン，テラマインン）飞よる皮下の線組細胞連合の変化飞 就いて。

Hiroshi YASUHARA 安原弘.

(Eingegangen am 24. November 1956.)

Die antibiotischen Agentien wirken, wie bekannt ist, direkt beschädigend auf Bakterien, aber auch, wenn im Tierkörper eingeführt, auf die Zellen des Körpers. In Japan konstatierten z. B. IMAMURA (1952), MITA (1953), TAKATA (1953) u. a., daß antibiotische Agentien die phagocytäre Tätigkeit der Leukocyten befördern. Auch konnten SHIRAHA und MIYAOKA (1953) bestätigen, daß Streptomycin die Fähigkeit der Farbstoffaufnahme des Retikuloendothelialsystems steigert. Das Retikuloendotherialsystem hat seinen Sitz in den Wänden der Blut- und Lymphbahn bestimmter Organe, während die Zellen der fibrohistiocytären Gemeinschaft sich weit in und um von verschiedenen Organen des Körpers befinden. Sie besteht vor allem aus den Fibrocyten, Fibrohistiocyten, Histiocyten und Monocyten im lockeren Bindegewebe (daher der Name), aber auch aus den Retikulumzellen, Retikulohistiocyten, Histiocyten, und Monocyten in der Schleimhaut. Die Zellgemeinschaft ist also ganz allgemein unter dem Namen ,retikulofibrohistiocytäre Gemeinschaft" zusammenzufassen. Die Zahl der Zellen ist beträchtlich groß, ebenso auch ihr Gesamtvolumen. Wenn sie daher alle an der Immunität Anteil nehmen, muß auch ihr Effekt sehr groß sein. Ich untersuchte also an der Maus, wie die fibrohistiocytäre Gemeinschaft sich durch die intravenöse Einführung von vier verschiedenen antibiotischen Agentien, Sarkomycin, Streptomycin, Achromycin und Terramycin verändert. Früher injizierten zwar NONAKA (1951) and INO (1952) Streptomycin in die Unterhaut der Maus und des Meerschweinchens und fanden eine Vermehrung der Histiocyten am Ort der Injektion und eine Zunahme der Tuberkelbacillen phagocytierenden Fähigkeit der Zellen, aber sie haben noch nicht die durch die Injektion hervorgerufenen Veränderungen von verschiedenen Zellen beobachtet. 


\section{Material und Methode.}

Die Versuche wurden an erwachsenen gesunden Mäusen von ungefähr $18 \mathrm{~g}$ angestellt. Man benutzte als die antibiotischen Agentien SarkomycinNatrium (von MEIJI-SEIKA), Dihydrostreptomycin-Sulfat (von DAINIPPON-SEIYAKU), Achromycin zur intravenösen Injektion (von LEDERLE) und Terramycin zur intravenösen Injektion (von PFIZER). Sie wurden mit physiologischer Kochsalzlösung so verdünnt, daß 0.1 cc Lösung 3.6, $0.7,0.6$, bzw. $0.6 \mathrm{mg}$ von den obigen Agentien enthielt. Man injizierte 0.1 cc Lösung einmal in die Schwanzvene der Maus. Die injizierte Agentienmenge wurde deswegen verschieden gemacht, weil ihre Giftigkeit für das Tier verschieden ist. In jeder 0.1cc Lösung war ein Fünftel der tödlichen Menge der Agentien enthalten, so daß die Giftwirkungen der Agentien auf das Tier beinahe die gleichen waren.

Die Tiere wurden 6 und 12 Stunden und 1, 2, 5 und 10 Tage nach der Injektion getötet. Man nahm ein kleines Stückchen des lockeren Bindegewebes aus der Unterhaut des Lendenteils, wobei man Fettgewebe und große Gefäße und Nerven vermied. Man breitete es innerhalb 10 Sekunden sanft auf dem Objektglas auf und legte sofort einen Tropfen von 10\% igem Formalin auf dem Häutchen auf. Es wurden noch ein paar Bindegewebshäutchen aus demselben Tier auf demselben Objektglas nebeneinander aufgestellt. Die Häutchen wurden nach Fixierung in einer großen Menge von $10 \%$ igem Formalin für 24 Stunden nach der Eisenhämateinlackmethode gefärbt.

\section{Ergebnisse und Auswertung.}

Vor der intravenösen Injektion.

Die Prozentzahlen der Fibrocyten, Fibrohistiocyten, Histiocyten, Monocyten und leukocytären Zellen im subkutanen Gewebe der normalen Mäuse finden sich in der Tabelle. Diese sind nahezu die gleichen wie von MUKOHATA (1941), MII (1941) und HORIE (1953). Man sehe hierzu Abb. 1. Es wurden jedesmal 500 Zellen gezählt.

\section{Stunden nach der intravenösen Injektion.}

Die fibrohistiocytäre Gemeinschaft in der Unterhaut wird bei allen antibiotischen Agentien aktiviert, und auf Kosten der Fibrocyten vermehren sich Fibrohistiocyten, Histiocyten und manchmal Monocyten und leukocytäre Zellen. Die Vermehrung von kleinen Histiocyten, Monocyten und leukocytären Zellen ist stark bei Sarkomycin (Abb. 2), etwas schwächer bei Achromycin (Abb. 4), und viel geringer bei den übrigen Agentien. Die Vermehrung der kleinförmigen Zellen, besonderes die der leukocytären Formen, ist aber bei den hier angewandten vier antibiotischen Agentien immer bei weitem geringer als bei der Penicillininjektion, die früher von 
Tabelle. Veränderung der fibrohistiocytären Gemeinschaft in der Unterhaut nach intravenöser Sarkomycin-, Streptomycin-,

Achromycin- und Terramycininjektion bei der Maus (\%).

\begin{tabular}{|c|c|c|c|c|c|c|c|c|}
\hline & \multirow{2}{*}{$\begin{array}{l}\text { Vor d. } \\
\text { Injek- } \\
\text { tion }\end{array}$} & \multicolumn{6}{|c|}{$\begin{array}{l}\text { Ablauf der Zeit nach der intravenösen } \\
\text { Injektion }\end{array}$} \\
\hline & & & $\begin{array}{c}6 \\
6 t d \\
\text { Std }\end{array}$ & $\begin{array}{l}12 \\
\text { Std. }\end{array}$ & $\begin{array}{c}1 \\
\text { Tag }\end{array}$ & $\begin{array}{c}2 \\
\text { Tage }\end{array}$ & $\begin{array}{c}5 \\
\text { Tage }\end{array}$ & $\begin{array}{c}10 \\
\text { Tage }\end{array}$ \\
\hline \multirow{5}{*}{ 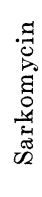 } & Fibrocyten & 73.0 & 59.0 & 45.8 & 47.2 & 55.0 & 66.4 & 71.0 \\
\hline & Fibrohistiocyten & 12.4 & 13.2 & 23.2 & 26.8 & 24.0 & 17.4 & 13.6 \\
\hline & Histiocyten & 12.8 & 16.4 & 26.8 & 23.8 & 18.4 & 13.2 & 12.4 \\
\hline & Monocyten & 0.8 & 4.8 & 1.8 & 1.0 & 1.2 & 2.0 & 1.8 \\
\hline & leukocytäre Z. & 1.0 & 6.6 & 2.4 & 1.2 & 1.4 & 1.0 & 1.2 \\
\hline \multirow{5}{*}{ 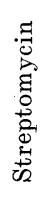 } & Fibrocyten & & 63.2 & 49.4 & 37.4 & 44.2 & 62.6 & 70.2 \\
\hline & Fibrohistiocyten & & 17.2 & 24.4 & 25.2 & 24.2 & 19.0 & 15.2 \\
\hline & Histiocyten & & 16.6 & 23.6 & 34.6 & 28.4 & 16.2 & 12.2 \\
\hline & Monocyten & & 0.8 & 1.2 & 1.0 & 1.0 & 0.8 & 1.0 \\
\hline & leukocytäre $Z$. & & 2.2 & 1.4 & 1.8 & 2.2 & 1.4 & 1.4 \\
\hline \multirow{5}{*}{ 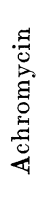 } & Fibrocyten & & 55.2 & 39.6 & 25.2 & 30.0 & 50.2 & 60.2 \\
\hline & Fibrohistiocyten & & 17.4 & 24.6 & 28.6 & 27.8 & 24.0 & 19.8 \\
\hline & Histiocyten & & 20.0 & 30.4 & 42.4 & 37.8 & 23.0 & 16.6 \\
\hline & Monocyten & & 3.8 & 2.8 & 2.0 & 2.0 & 1.2 & 1.8 \\
\hline & leukocytäre $Z$. & & 3.6 & 2.6 & 1.8 & 2.4 & 1.6 & 1.6 \\
\hline \multirow{5}{*}{ 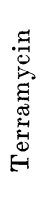 } & Fibrocyten & & 52.0 & 40.2 & 23.6 & 32.2 & 46.0 & 59.2 \\
\hline & Fibrohistiocyten & & 21.8 & 26.2 & 30.0 & 28.8 & 26.2 & 20.2 \\
\hline & Histiocyten & & 21.4 & 29.0 & 42.6 & 36.0 & 24.8 & 17.4 \\
\hline & Monocyten & & 2.4 & 2.0 & 1.8 & 1.4 & 1.2 & 1.6 \\
\hline & leukocytäre $Z$. & & 2.4 & 2.6 & 2.0 & 1.6 & 1.8 & 1.6 \\
\hline
\end{tabular}

HORIE (1953) vorgenommen wurde. Es scheint also ihre Reizwirkung auf die fibrohistiocytäre Gemeinschaft (Abb. 2-5) viel schwächer zu sein als die von Penicillin.

12 Stunden nach der intravenösen Injektion.

Die Veränderungen erscheinen stärker. Die fibrohistiocytären und histiocytären Zellarten nehmen an Zahl zu. Größere Formen von ihnen vermehren sich auch. Die Zahl der früher mehr oder weniger vermehrten kleinen Zellen vermindert sich, und alle Übergangsformen zwischen ihnen sind zu sehen. Bei Sarkomycin erreichen die Histiocyten schon in diesem Stadium die Höchstzahl (Abb. 6).

1 Tag nach der intravenösen Injektion.

Bei der Achromycin- und Terramycininjektion vermehren sich die typischen großen Histiocyten anfallend. Die Fibrohistiocyten and Histio- 
cyten machen die Mehrzahl der Zellen aus. Die Zahl der Fibrocyten ist beträchtlich vermindert. Die meisten von ihnen ähneln nunmehr mehr oder weniger den Fibrohistiocyten (Abb. 8 und 9).

Bei der Streptomycininjektion treten die Veränderungen prinzipiell in der gleichen Weise auf, aber die Vermehrung der Fibrohistiocyten und Histiocyten stehen, wie in Abb. 7 gezeigt ist, an Stärke hinter derjenigen bei den obigen zwei Agentien. Bei den obigen drei Agentien erreicht die Vermehrung der Fibrohistiocyten und Histiocyten in diesem Stadium das Maximum. Bei der Sarkomycininjektion entstehen aber zahlreiche Vakuolen im Cytoplasma der Fibrohistiocyten und Histiocyten. Auch bezüglich des Zahlenverhältnisses der Zellen findet sich die fibrohistiocytäre Gemeinschaft schon auf dem Wege der Wiederkehr zum früheren Zustand.

Die kleinen Zellen, wie Monocyten und leukocytäre Zellen, sind an Zahl gering (Abb. 7-9).

\section{Tage nach der intravenösen Injektion.}

Bei allen antibiotischen Agentien vermindern sich die Histiocyten, und anstatt deren vermehren sich die Fibrohistiocyten. In den Histiocyten und besonders in den Fibrohistiocyten werden die Vakuolen größer, indem kleinere Vakuolen sich miteinander vereinigen. Eine große Vakuole, die sich dem Kern benachbart findet, drückt bisweilen eine Seite des Kerns und deformiert ihn (Abb. 16). Große Vakuolen, die am Rand des Zelleibes liegen, ragen oft mit dünner Haut bedeckt nach außen vor (Abb. 15). Solche Vakuolen platzen häufig und entleeren ibren Inhalt, so daß also der Rand der Fibrohistiocyten nicht glatt wird (Abb. 13). Nicht selten werden auch solche Fibrohistiocyten und Histiocyten gefunden, aus deren Zelleib sich kleine Teile des Cytoplasmas mit oder ohne Vakuolen, abschnüren und abtrennen, wie man es in Abb. 16 (in der Zeit 5 Tage nach der Achromycininjektion) sieht. Es gibt also zwei Wege der Absonderung von Vakuolen aus den Fibrohistiocyten und Histiocyten. Es ist nicht klar, ob dies auf der Differenz der Beschaffenheit der Zellen oder auf der Differenz der Bedingungen des äußeren Mediums beruht. Vielleicht auf beiden. Es ist aber sicher nicht durch die Differenz der Antibiotika bedingt, weil die beiden Vakuolenabsonderungsweisen bei allen Antibiotika gleichfalls zustande kommen.

\section{Tagen nach der intravenösen Injektion.}

Die Fibrocyten vermehren sich. Die Vakuolen liegen noch, wie in Abb. 10-12 gezeigt ist, reichlich im Cytoplasma der Fibrocyten und Fibrohistiocyten. Das Platzen der Vakuolen und das Abschnüren von Teilen des Cytoplasmas der Fibrohistiocyten und Histiocyten, welche man 2 Tage nach der intravenösen Injektion bemerkt hat, finden immer noch lebhaft statt (Abb. 14 und 16). 


\section{Tage nach der intravenösen Injektion.}

Das Zellbild kehrt annähernd zur Norm zurück, nur daß nach der Achromycin- und Terramycininjektion sich Vakuolen noch zahlreich in den Zellen finden und das Záhlenverhältnis der Zellen noch nicht ganz normal ist.

$\mathrm{Zu}$ bemerken ist, daß die Vermehrung der Zellen nicht nur die Folge der direkten Wirkung der intravenösen Injektion der antibiotischen Agentien, sondern auch bis zu einem gewissen Grade die der sekundären Reize von Gewebsveränderungen ist. Die Monocyten und lenkocytären Zellen treten also nicht nur in dem obigen ganzen Verlauf, sondern auch nach dem Abklingen der Wirkung der antibiotischen Agentien lang dauernd, wenn auch gering, vermehrt im Bindegewebe auf.

Faßt man die obigen Ergebnisse zusammen, so ist zu sagen, daß die Vermehrung der Fibrohistiocyten und Histiocyten bei Achromycin und Terramycin, die sich mit den breitesten Spektra* der angreifenden Bakterien ausstatten, am stärkesten ist. Die Vermehrung der Zellen ist bei Streptomycin etwas geringer. Bei Sarkomycin, welches eher ein antineoplastisches Antibioticum und von einer bei weitem schwächeren antibakteriellen Wirkung ist, ist die Zellvermehrung noch viel geringer. Weil die Fibrohistiocyten und Histiocyten kräftig gegen die pathogenen Bakterien abwehrend wirken, so müssen die antibiotischen Agentien, welche sie im Körper stark vermehren, neben der direkten antibakteriellen Wirkung anch indirekte Wirkung auf dem Wege der Zellmobilisierung ausüben. Bei genauerer Untersuchung stellt man fest, daß die Fibrohistiocyten und Histiocyten im Ablauf von 2-5 Tagen nach der Injektion Vakuolen reichlich im Zelleib bilden und den Inhalt nach außen absondern oder aber, wie es vor kurzem ROBERTSON (1952) in dem an der Ohrmuschel des Kaninchens angebrachten durchsichtigen Fenster bestätigen konnte, einen Teil des Cytoplasmas mit oder ohne Vakuolen aus den Zellen trennen lassen. Nach der Untersuchung von SAWACHIKA (1950), KAMISAKA (1951) u. a. m. enthalten die Auszüge aus den Zellen der fibrohistiocytären Gemeinschaft reichlich antibakterielle Substanzen. Das Cytoplasma der Fibrohistiocyten und Histiocyten ist wahrscheinlich gerade mit solchen Substanzen reich ausgestattet. Für die meisten pathogenen Bakterien ist gewiß die Siedelung an dem an diesen Cytoplasma- und Vakuolensubstanzen reichen Ort schwierig.

* Die Breite der Reihe von gewissen durch ein chemotherapeutisches oder antibiotisches Mittel angreifbaren Bakterienarten in der Reihe von aneinander gelegenen ganzen Bakterien, genau wie die Breite von gewissen Spektralfarben in der Spektrareihe. 


\section{Zusammenfassung.}

Es wurden der Maus die im Titel angegebenen vier Antibiotika intravenös injiziert und Stückchen des Unterhautbindegewebes nach Ablauf von verschiedenen Zeiten entnommen, um die Veränderungen der fibrohistiocytären Gemeinschaft an Häutchenpräparaten zu untersuchen. Die intravenöse Injektion der Antibiotika ruft eine mehr oder weniger starke Vermehrung von bakterienfeindlichen Fibrohistiocyten und Histiocyten hervor. Die Antibiotika von breiteren antibakteriellen Spektra mobilisieren dabei die Zellen stärker. Die Antibiotika greifen also im Tierkörper nicht nur unmittelbar an Bakterien an, sondern auch auf dem indirekten Wege durch die Aktivierung der fibrohistiocytären Gemeinschaft. In der Zeit 2-5 Tage nach der Injektion der Antibiotika erscheinen zahlreiche Vakuolen in den bakterienfeindlichen Fibrohistiocyten und Histiocyten. Große Vakuolen platzen oft nach außen. Es wird aber auch nicht selten ein Teil des Cytoplasmas mit oder ohne Vakuolen von dem Zelleib abgeschnürt. Die die Zellen umliegende Gegend wird naturgemäß für die Siedelung von den meisten Bakterien ungeeignet.

\section{内 容自 抄.}

二十日鼠飞標題の 4 種の抗生物質を静注し，時間の経過を追ってその皮 下組織を観察した。抗生物質は何れも皮下の線組細胞連合を刺戟して菌敵 である線組球と組織球を多少強く増加させた. 特と抗囷性スペクトルムが 広いものほどそれを増加させることが著しかった。 そこで抗生物質は身体 内で細菌に直接害するほかに，これ等の菌敵細胞を動員することにより間 接に細菌に抗することになる，注射後 2 -5 日頃に菌敵の 線組球と組織球 飞多数の空胞が現れ，その大きなるのが破裂して内容を細胞外飞放出し， また胞体の一部が小さな空胞を持ち又は持たないま〉細胞から緻断される のが屢ば見られる.故にその界隈は当然大概の細菌の生存に適当しないこ とになろう。

\section{Literatur.}

Horie, M.: Über die durch die intravenöse Injektion von Penicillin verursachte Aktivierung des fibrohistiocytären Systems der Maus und des Kaninchens und über das Auftreten der mit einem mannigfaltig gestalteten Ringkern versehenen leukocytären Zellen bei der Maus. Arch. hist. jap. 4 (1953). - Imamura, S.: Experimental study on influence of various kinds of antibiotic agent on the leucocytes. (Jap. m. engl. Zfass.) Bull. Inst. Balneother. 3 (1951). - Ino, I.: Studies on alteration of tissue by streptomycin treatment. Trans. Soc. path. jap. 
41. Edit. gen. (1952). - Kamisaka, O.: Comparative studies on the destructive actions of the reticuloendothelial and fibrohistiocytic systems on bacteria in living animals. Arch. hist. jap. 2 (1951). - Mii, Y.: Veränderungen der Zellen im subkutanen Bindegewebe der Maus bei der Injektion von Arzneimitteln. I. Jap. J. med. Sci. 9 (1942). - II. Jap. J. med. Sci. 10 (1942). — Mita, H.: Versuche über die morphologischen Veränderungen der Bakterien unter der Wirkung des Antibiotikums. (Jap.) Medicine. 14 (1953). - Mukohata, J.: Experimentelle Untersuchungen über die Umwandlungsfähigkeit der Zellen im Subkutangewebe der Maus. III-IV. Okajimas. Fol. 20 (1941). - Nonaka, H.: Effect of streptomycin on tissue cells especially on their phagocytic activity in experimental studies. (Jap. m. engl. Zfass.) Acta. path. jap. 1 (1951). - Robertson, J. S.: The response of the macrophage to antigenic azoprotein, studied in the rabbit ear chamber preparation. Austral. J. exper. Biol. a. med. Sci. 30 (1952). - Sawachika, H.: Effects of fibrohistiocytic system extract on bacteria. Arch. hist. jap. 1 (1950). - Siraha, Y. u. T. Miyaoka : Effect of antibiotics on reticuloendothelial function. (Jap.) J. Antibiotics. 5 (1952). - Takata, I.: Effect of antibiotics on phagocytosis. I. (Jap.) J. Antibiotics, Ser. B. 6 (1953). 


\section{Erläuterung zu den Tafelabbildungen.}

Abb. 1-16. Subkutangewebe der Maus. Färbung von formalinfixierten Häutchenpräparaten mit Eisenhämateinlack.

Abb. 1. Vor der intravenösen Injektion. $70 \times$.

Abb. 2. 6 Stunden nach der intravenösen Sarkomycininjektion. $70 \times$. 


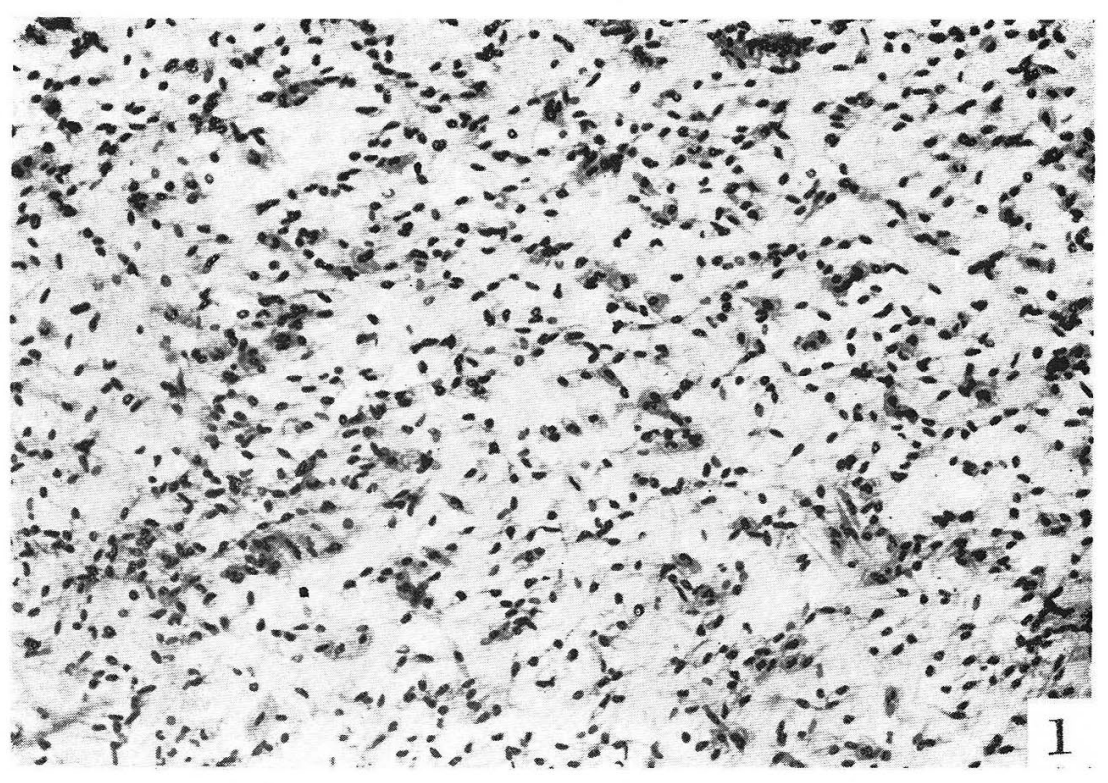

50 ond -

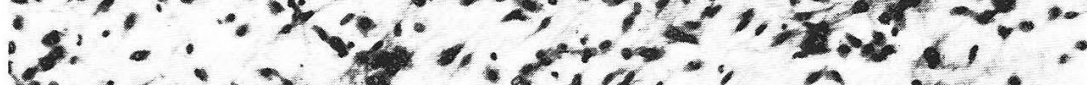

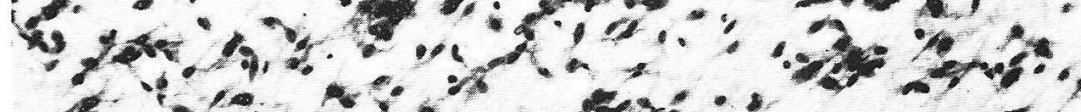
ats o

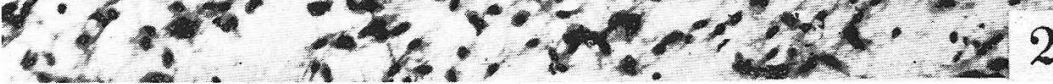


Abb. 3. 6 Stunden nach der intravenösen Streptomycininjektion. $70 \times$.

Abb. 4. 6 Stunden nach der intravenösen Achromycininjektion. $70 \times$. 


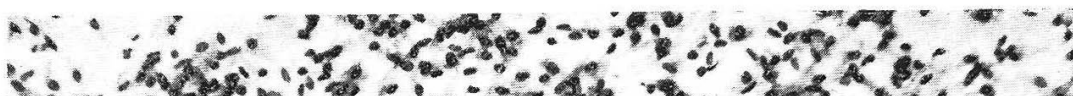

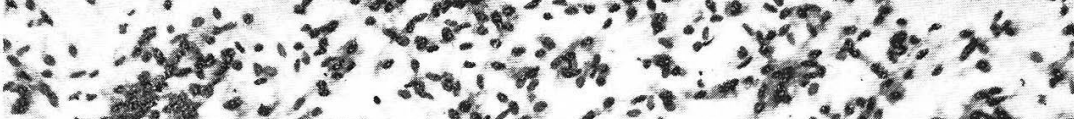
1.

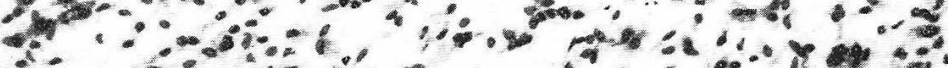

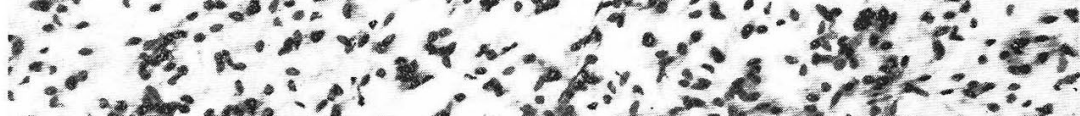

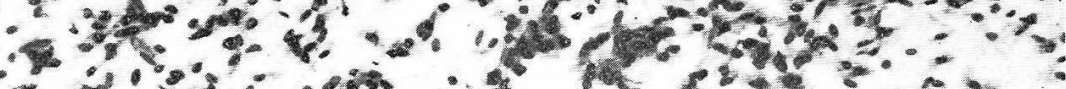
- - -

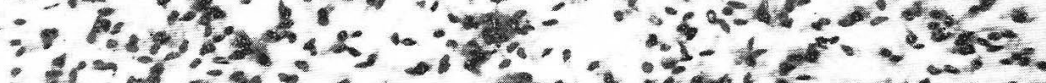

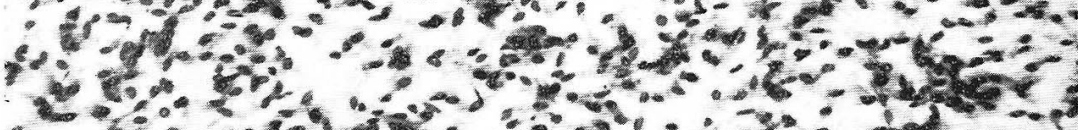
F.

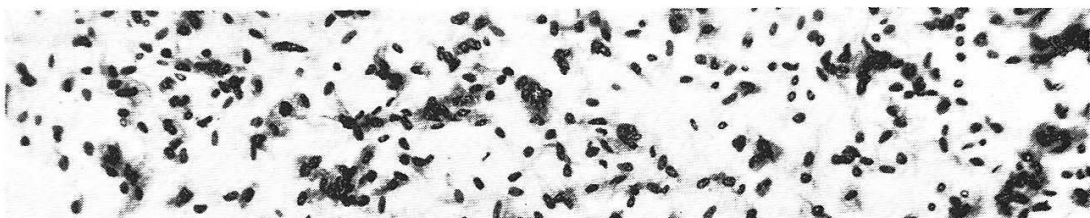

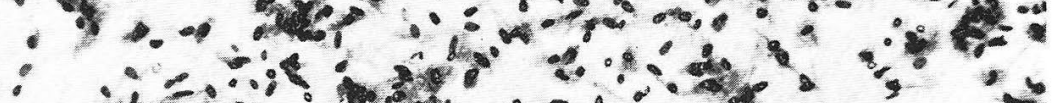

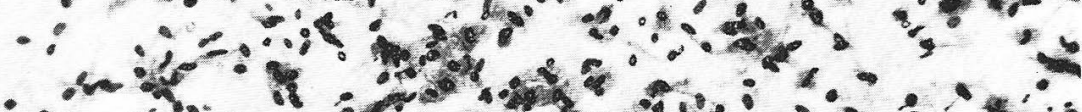

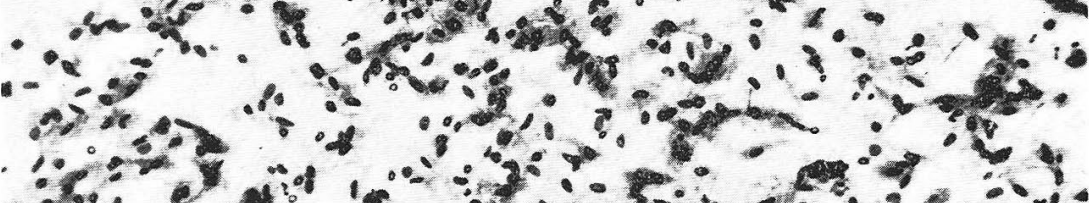

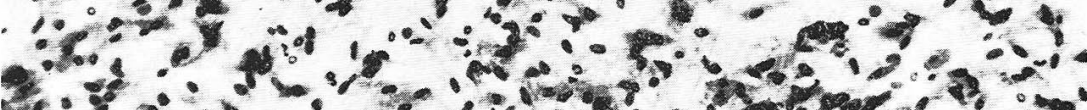

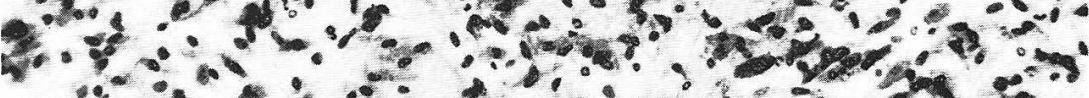

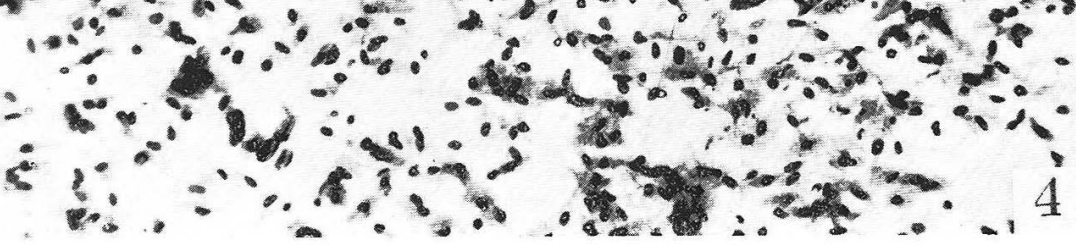


Abb. 5. 6 Stunden nach der intravenösen Terramycininjektion. $70 \times$.

Abb. 6. 12 Stunden nach der intravenösen Sarkomycininjektion. $70 \times$. 


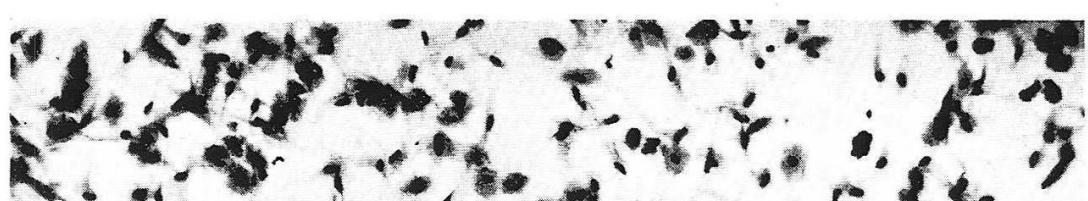

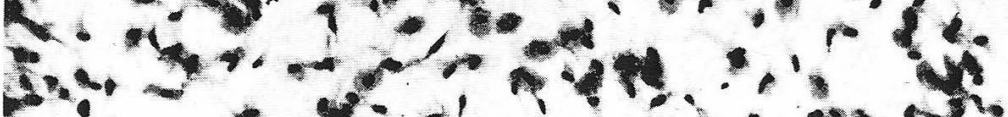

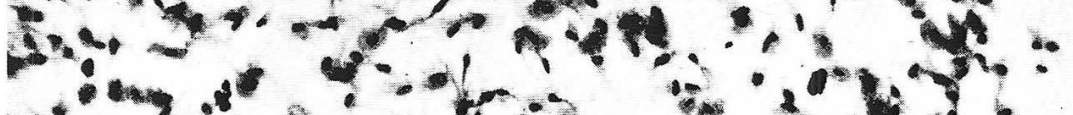

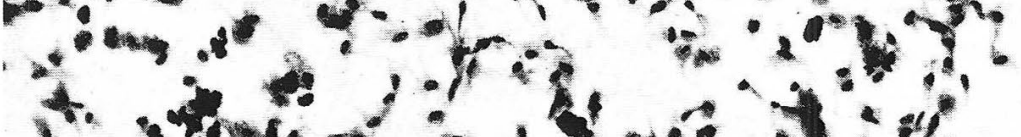

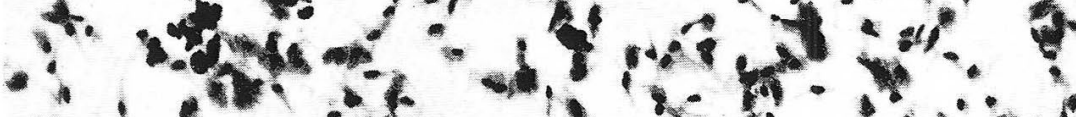

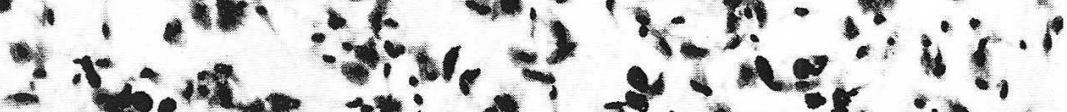

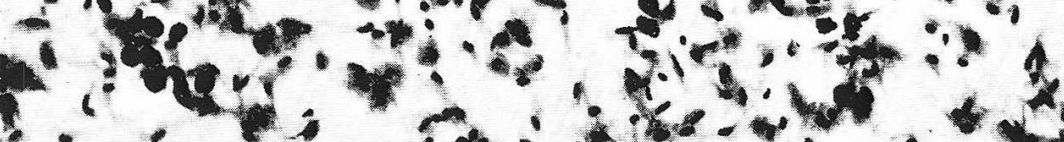

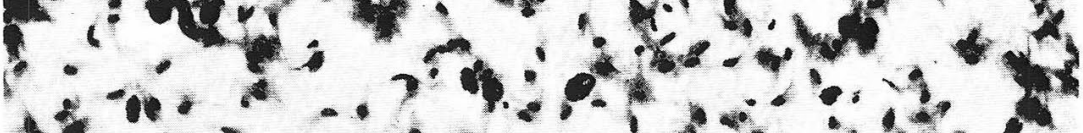
4.

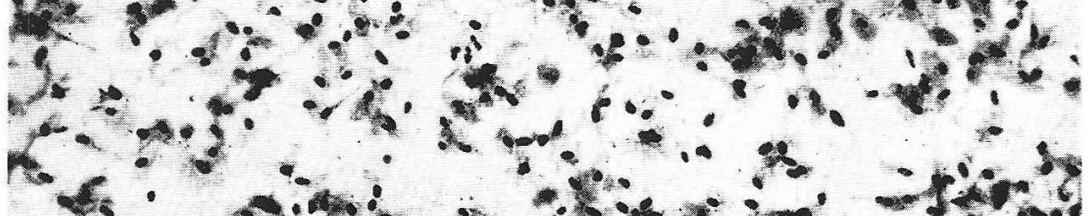

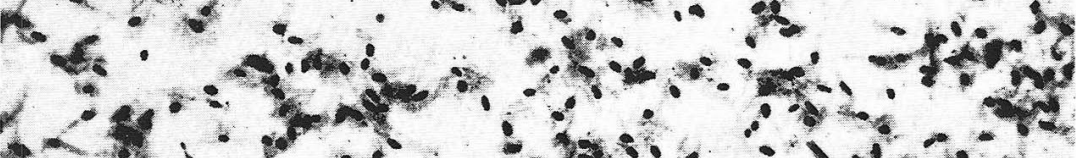

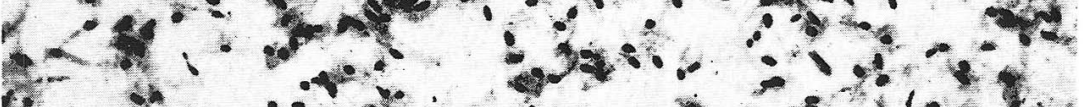

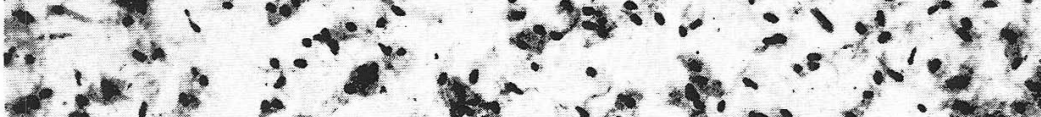

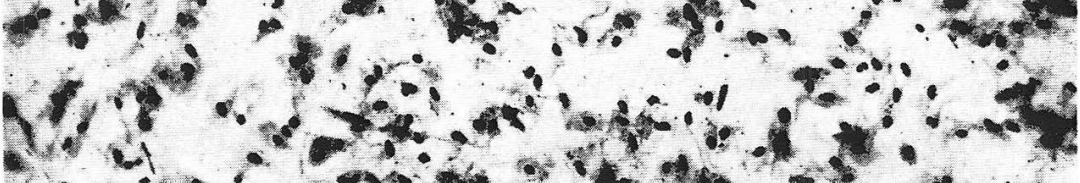

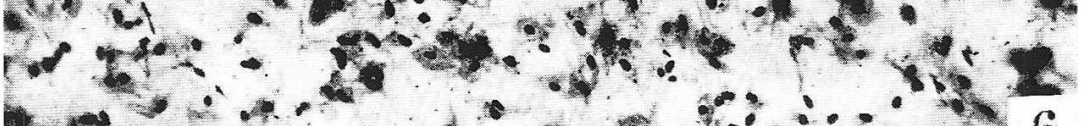

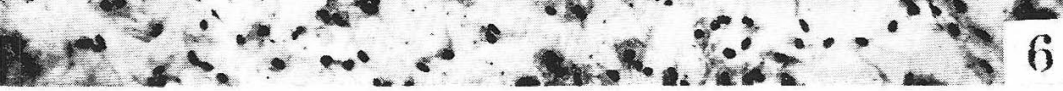


Abb. 7. 1 Tag nach der intravenösen Streptomycininjektion. $70 \times$

Abb. 8. 1 Tag nach der intravenösen Achromycininjektion. $70 \times$. 
1.

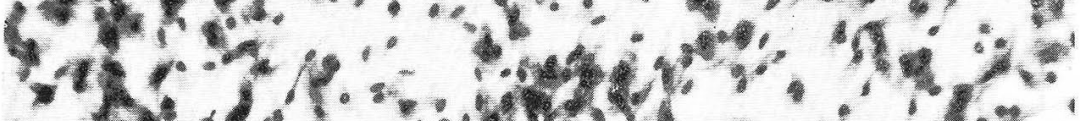
6.5.

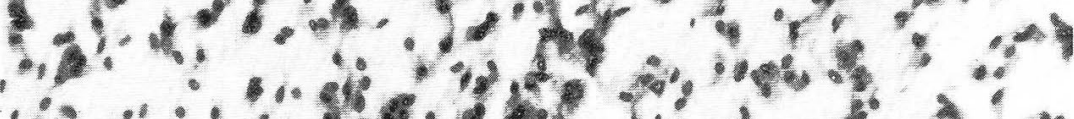
F. 4. 1.

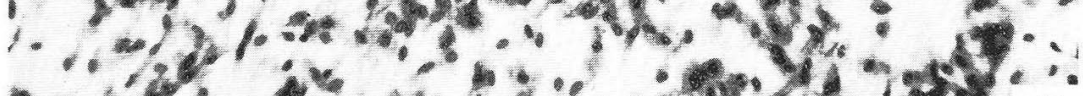

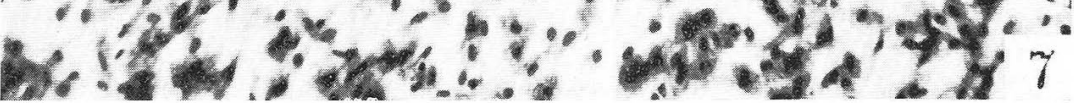

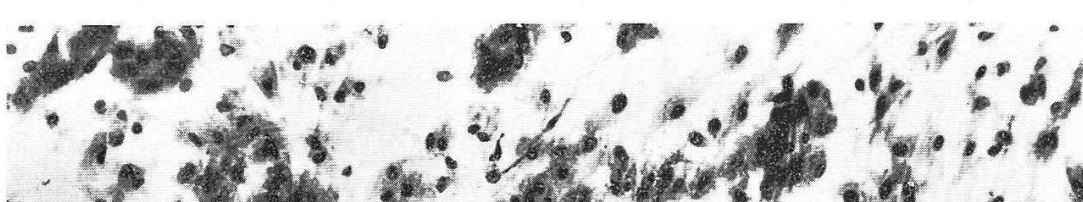

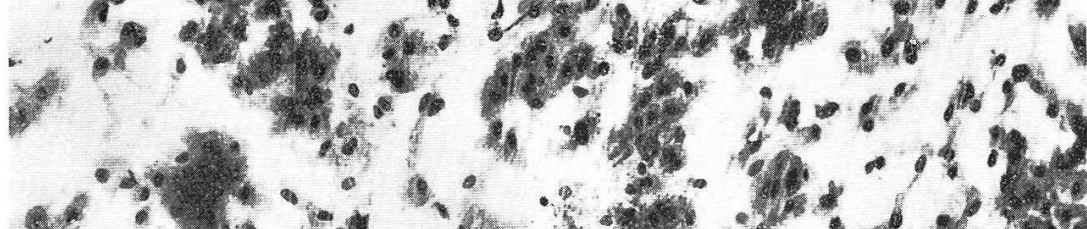

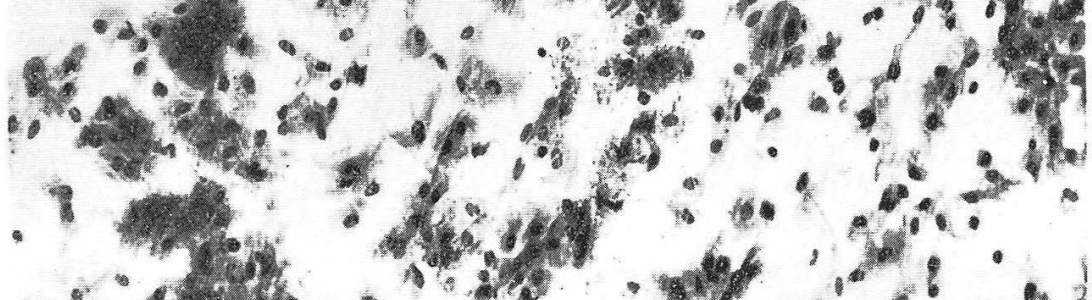

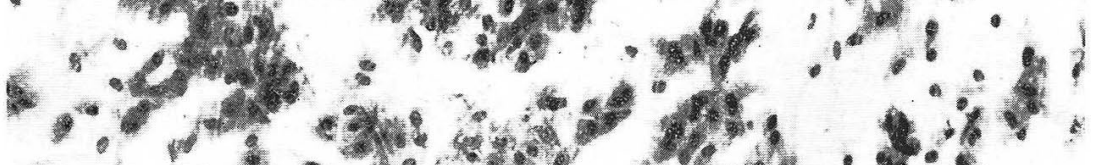

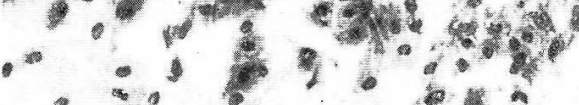
$-1,2$.

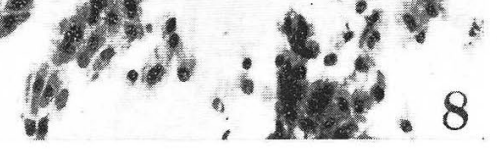


Abb. 9. 1 Tag nach der intravenösen Terramycininjektion. $70 \times$.

Abb. 10. 5 Tage nach der intravenösen Streptomycininjektion. $70 \times$. 

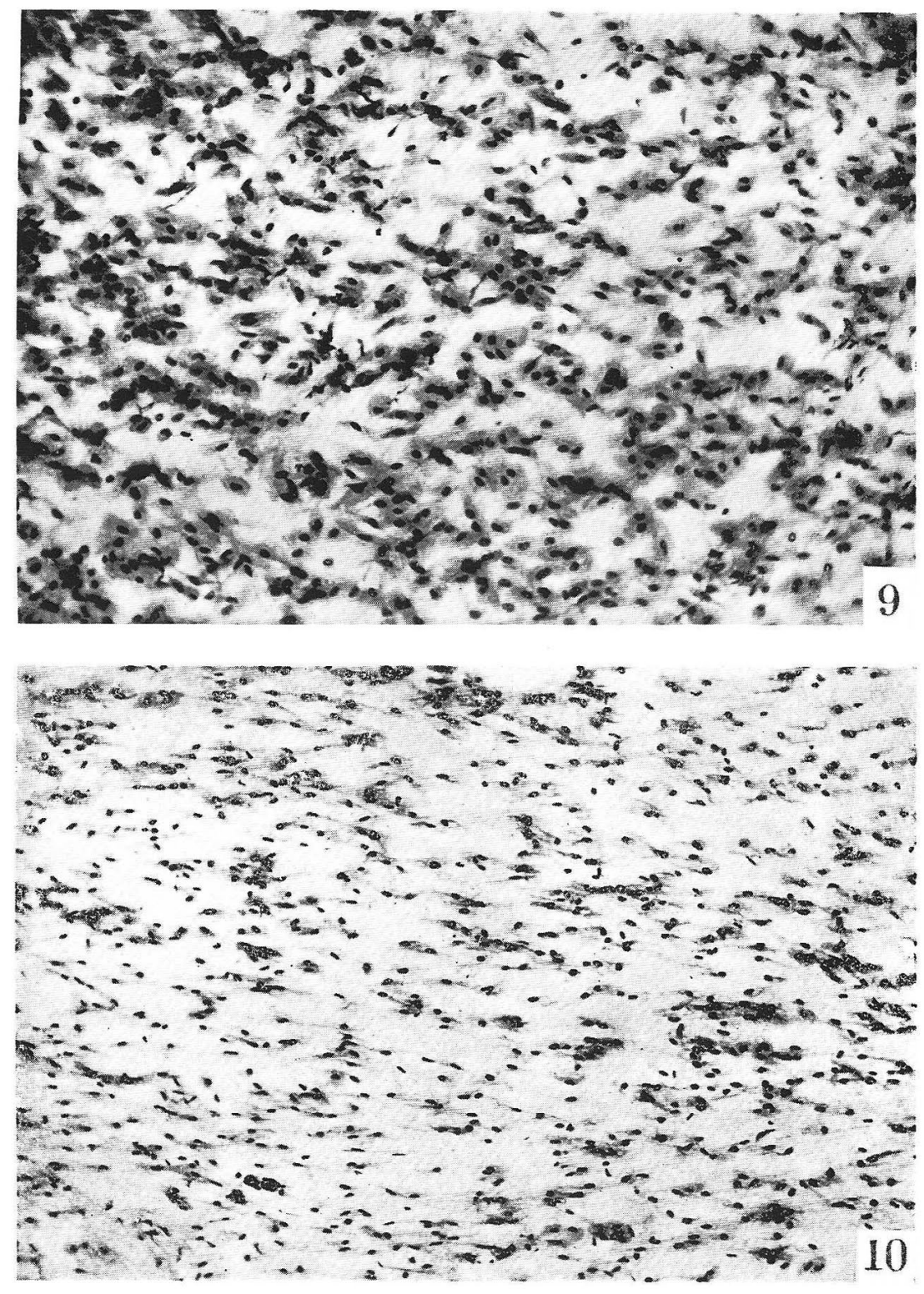
Abb. 11. 5 Tage nach der intravenösen Achromycininjektion. $70 \times$.

Abb. 12. 5 Tage nach der intravenösen Terramycininjektion. $70 \times$. 

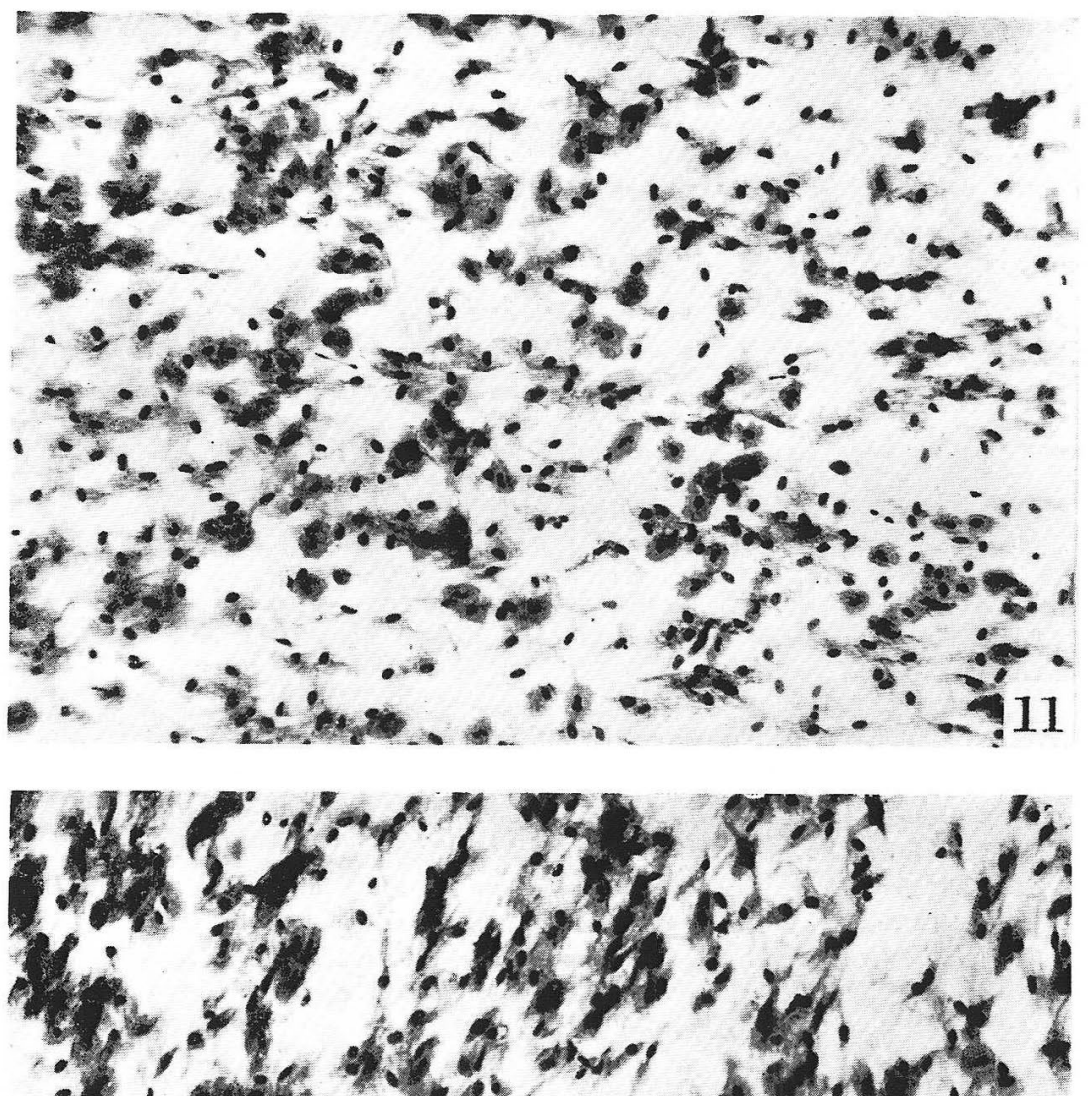

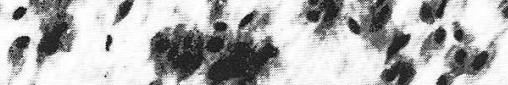

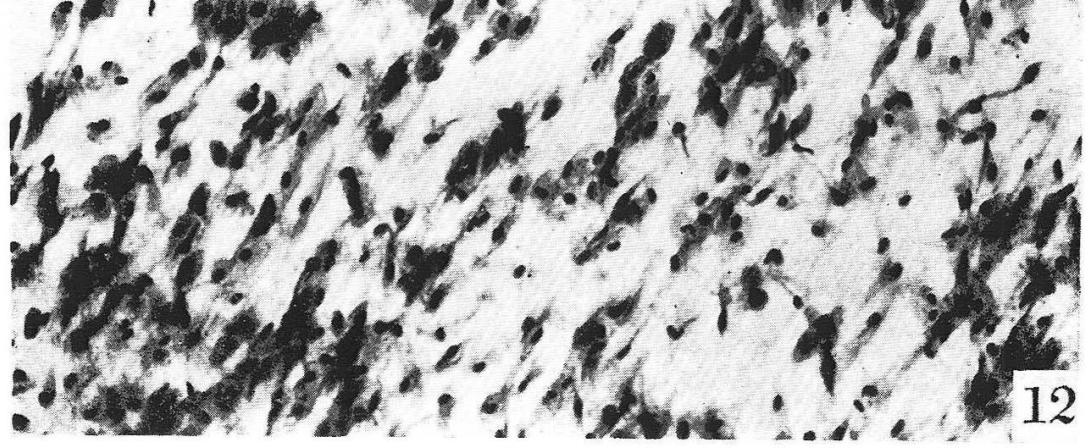


Abb. 13. 2 Tage nach der intravenösen Streptomycininjektion. Vakuolen am Rand der Histiocyten sind geplatzt. Die Kontur der Zellen ist nicht glatt. $1100 \times$.

Abb. 14. 5 Tage nach der intravenösen Streptomycininjektion. Man sieht große Vakuolen in den Fibrohistiocyten. 1100 $\times$.

Abb. 15. 2 Tage nach der intravenösen Achromycininjektion. Dicht unter der Zellmembran eines Fibrohistiocyten bildet sich eine große Vakuole und ragt nach außen vor. $1100 \times$.

Abb. 16. 5 Tage nach der intravenösen Achromycininjektion. Abschnüren eines Teils des Cytoplasmas von den Fibrohistiocyten und Histiocyten, und Deformierung des Kerns infolge des Druckes einer Vakuole. $1100 \times$. 
H. YASUHARA (7)
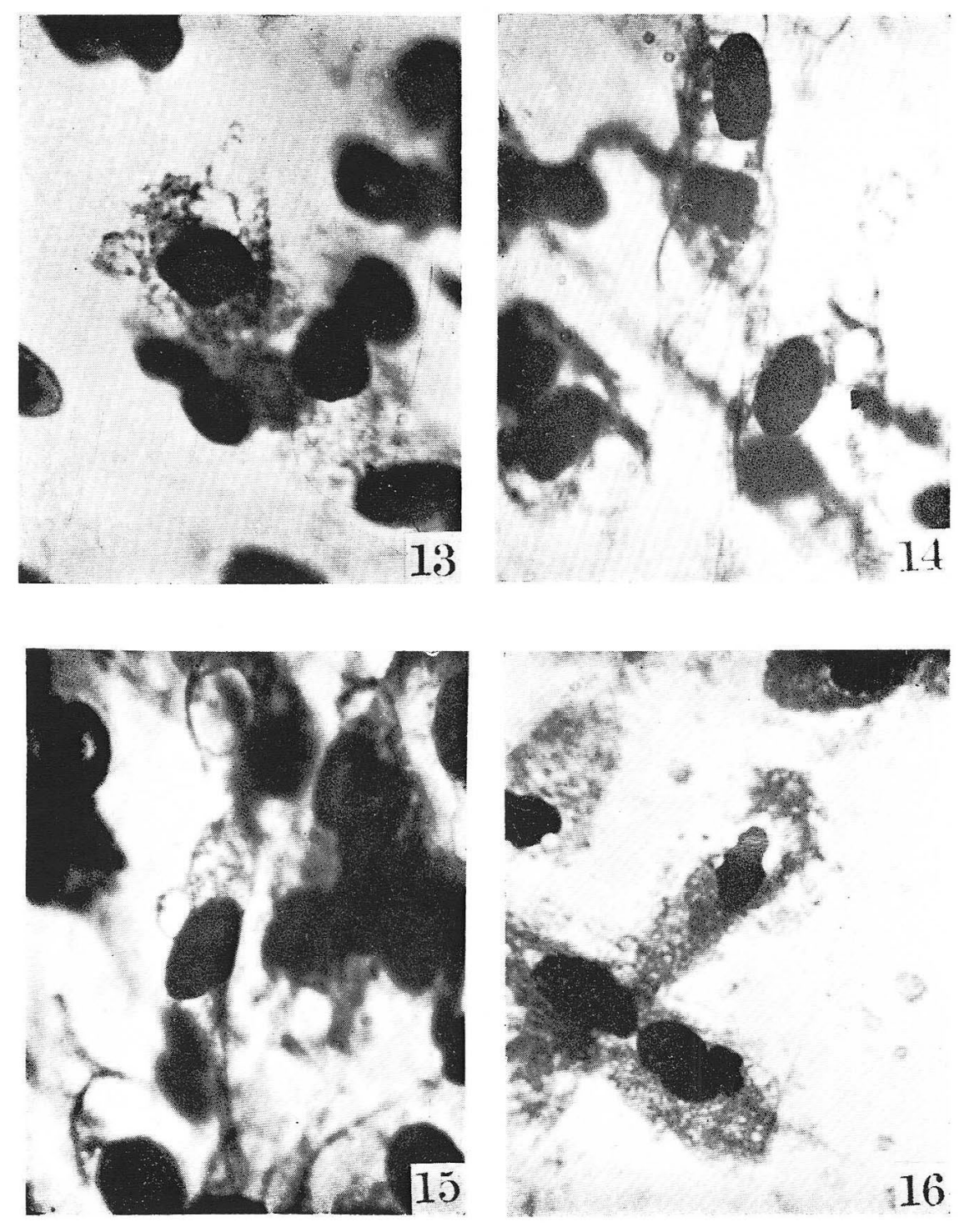